\title{
Tecnologias para tratamento aeróbio de resíduos sólidos orgânicos domiciliares
}

Esta pesquisa teve como objetivo desenvolver e adaptar tecnologias de tratamento biológico aeróbio de resíduos sólidos orgânicos domiciliares, de maneira a favorecer a implantação em domicílios e condomínios contemplando os princípios de sustentabilidade e tecnologia social. O trabalho foi dividido em cinco etapas: Contato com as famílias; Estruturação e montagem da área experimental; Desenvolvimento e adaptação de tecnologias para tratamento biológico aeróbio de resíduos sólidos orgânicos; Coleta dos resíduos sólidos orgânicos nas residências; Tratamentos dos resíduos sólidos orgânicos. Este tipo de resíduo apresenta altos valores de matéria orgânica e de umidade, além de organismos patógenos. Foram adotados dois modelos de tecnologia de tratamento: composteira de polietileno cilíndrica (CPC) e composteira de alumínio retangular (CAR). As tecnologias de tratamento apresentaram comportamento diferenciado em relação à diversidade de organismos e em relação aos parâmetros físicos e químicos, verificando-se que a configuração das composteiras tem influência sobre os mesmos. Ao considerar o tempo de estabilização, facilidade de operação, aplicação em pequena escala e a qualidade do composto final, o modelo CPC mostrou-se mais eficiente. Portanto, as tecnologias estudadas foram viáveis ao alcance dos objetivos esperados para o tratamento biológico aeróbio de resíduos sólidos orgânicos domiciliares: estabilização e higienização da parcela orgânica com espaço de tempo médio inferior a 80 dias.

Palavras-chave: Meio ambiente; Tecnologia; Compostagem; Resíduos sólidos orgânicos.

\section{Technology for aerobic treatment of home organic solid waste}

\begin{abstract}
This research aimed to develop and adapt technologies for aerobic biological treatment of household solid organic waste, in order to favor the implantation in homes and condominiums contemplating the principles of sustainability and social technology. The work was divided into five stages: Contact with families; Structuring and assembly of the experimental area; Development and adaptation of technologies for aerobic biological treatment of organic solid waste; Collection of solid organic residues in homes; Treatments of organic solid waste. This type of waste has high values of organic matter and moisture, as well as pathogenic organisms. Two treatment technology models were adopted: cylindrical polyethylene composites (CPC) and rectangular aluminum composites (CAR). The treatment technologies showed different behavior in relation to the diversity of organisms and in relation to the physical and chemical parameters, verifying that the configuration of the composters has influence on them. When considering the stabilization time, ease of operation, small scale application and the quality of the final compound, the CPC model proved to be more efficient. Therefore, the technologies studied were feasible to achieve the objectives expected for the aerobic biological treatment of household organic solid waste: stabilization and hygiene of the organic portion with an average time span of less than 80 days.
\end{abstract}

Keywords: Environment; Technology; Composting; Organic solid waste.

Topic: Desenvolvimento, Sustentabilidade e Meio Ambiente

Reviewed anonymously in the process of blind peer
Received: 01/01/2021

Approved: $28 / 01 / 2021$
Ivanise Gomes (iD

Universidade Estadual da Paraíba, Brasil http://lattes.cnpq.br/6042837219372011 http://orcid.org/0000-0003-4561-8739 ivanisegomesbio@gmail.com

Mônica Maria Pereira da Silva (iD) Universidade Estadual da Paraíba, Brasil http://lattes.cnpq.br/8972860324282858 http://orcid.org/0000-0002-1593-1698 monicaea@terra.com.br

Rosilene Barros Gomes (iD

Universidade Estadual da Paraíba, Brasil http://lattes.cnpq.br/0880366224800498 http://orcid.org/0000-0001-8086-8851 rosilene barrosgomes@hotmail.com

\begin{abstract}
Fernando Luiz Barbosa Farias
Universidade Estadual da Paraíba, Brasil http://lattes.cnpq.br/5564372426013611 fernando.luiz.2327@gmail.com
\end{abstract}

Elaine Cristina dos Santos Araujo (id

Universidade Estadual da Paraíba, Brasil

http://lattes.cnpq.br/1224773257521776 http://orcid.org/0000-0002-6288-8469

crys lainne@yahoo.com.br

\section{Adrianne Teixeira Barros (iD)}

Universidade Estadual da Paraíba, Brasil http://lattes.cnpq.br/3228203365280543 http://orcid.org/0000-0002-7393-642X

adriannebarros@yahoo.com.br

\section{Referencing this:}

GOMES, I.; SILVA, M. M. P.; GOMES, R. B.; FARIAS, F. L. B.; ARAUJO, E. C. S.; BARROS, A. T.. Tecnologias para tratamento aeróbio de resíduos sólidos orgânicos domiciliares. Revista Ibero Americana de Ciências Ambientais, v.12, n.1, p.544-557, 2021. DOI:

DOI: 10.6008/CBPC2179-6858.2021.001.0044 http://doi.org/10.6008/CBPC2179-6858.2021.001.0044 


\section{INTRODUÇÃO}

Com as mudanças nos padrões socioeconômicos, agregadas às inovações tecnológicas, a sociedade contemporânea passou a gerar uma heterogeneidade de resíduos sólidos, resultando na sobrecarga dos sistemas ambientais, ultrapassando desse modo, a capacidade de suporte do planeta Terra. Em consequências, vários impactos negativos são vivenciados, impondo aos gestores públicos e a população em geral, alterações no seu modo de produção e de consumo.

A geração crescente de resíduos sólidos e a quantidade de matéria orgânica que é descartada produzem passivos ambientais que suscitam em riscos e comprometem os recursos naturais. Além de afetar as esferas sociais e econômicas (HASSEN et al., 2001; CAMPITELLI, 2010; VILLAMIZAR, 2014; GAMA et al., 2019) e a saúde humana (SILVA, 2020). O uso indiscriminado dos recursos ambientais e a disposição inadequada dos subprodutos gerados comprometem os princípios que devem nortear o desenvolvimento sustentável, além de contrariar o que estabelece o art. 225 da Constituição Federal, satisfazer às necessidades do presente sem lesar as futuras gerações (BRASIL, 1988).

A disposição final de resíduos sólidos de forma imprópria ocasiona diferentes tipos de poluição: da água e do solo através da lixiviação de resíduos sólidos biodegradáveis e do ar com a emissão de gases que constituem o efeito estufa (EJAZ et al., 2010; HAMILTON et al., 2013). Acarretam também problemas sanitários, uma vez que, propiciam condições favoráveis à proliferação de vetores causadores de doenças como: diarreias infecciosas, amebíase, salmoneloses e helmintoses (BRASIL, 2007; YOADA et al., 2014). Destacam-se, nesse contexto, as doenças relacionadas ao mosquito Aedes aegypti, como dengue, zika e chikungunya (SILVA, 2016; 2020).

Como forma de eliminar ou minimizar os impactos negativos causados pela crescente produção e disposição indevida dos resíduos sólidos, ressalta-se a gestão integrada, conceituada como um conjunto de ações voltadas para encontrar soluções para os resíduos sólidos, de forma que haja redução ou eliminação dos impactos adversos (OLIVEIRA et al., 2007; BRASIL, 2010; SILVA, 2020). Segundo Silva et al. (2020) os objetivos da gestão de resíduos sólidos não serão alcançados, sem a mudança de percepção ambiental equivocada e os padrões de produção e de consumo prevalecentes no modelo de sociedade vigente. A autora considera que Educação Ambiental é imperiosa à obtenção dessas mudanças.

A separação dos resíduos sólidos na fonte geradora, uma das ações que constitui a gestão integrada de resíduos, é indicada como o método mais apropriado e eficiente na realização de níveis mais elevados de reciclagem (MARGARITIS et al., 2018; SILVA et al., 2019; SILVA et al., 2020). Através da reciclagem, a parcela orgânica que antes era misturada aos demais materiais e considerada "lixo", passam a terem agregados valores e retornam ao ciclo produtivo, através da sua conversão em composto mediado por diferentes organismos (MISHRA et al., 2003; ARAÚJO et al., 2019; SILVA et al., 2020a).

A compostagem é um processo biológico de transformação rápida da matéria orgânica em condições aeróbias e controladas; realizado num período de tempo ajustado. Por meio desse processo, obtém-se um produto chamado de composto, que pode ser utilizado em solos como fonte de nutrientes, reduzir a erosão, 
a acidez e melhorar o escoamento superficial, além de ser benéfico à produtividade em hortas e jardins (CASTALDI et al., 2008; VALENTE et al., 2009; CAMPITELLI, 2010; ARAÚJO et al., 2019; SILVA et al., 2020b).

Torna-se evidente que o tratamento da fração orgânica é indispensável à eficiência da gestão ambiental das municipalidades brasileiras, tendo em vista os efeitos negativos sobre meio ambiente e saúde humana. Haja vista que os resíduos sólidos orgânicos reúnem condições favoráveis à ação de uma diversidade de organismos, dentre os quais, os patogênicos, como mencionam Silva et al. (2010), Chandna et al. (2013), Heck et al. (2013), Araújo et al. (2019) e Silva et al. (2020).

Para superar essas preocupações convém aos gestores públicos e a população em geral mudanças que desencadeiem atitudes e práticas mais sustentáveis para o tratamento dos resíduos sólidos, de maneira que conservem os recursos naturais e reduzam os impactos ambientais negativos.

Entre as várias opções de tratamento de resíduos sólidos, a tecnologia de compostagem descentralizada tem sido vista como uma importante promessa na gestão de resíduos sólidos orgânicos, de forma sustentável (ARAÚJO et al., 2019; SILVA et al., 2020b). Em particular para os países em desenvolvimento, por ser uma tecnologia simples e de baixo custo econômico.

Segundo as diretrizes da Lei $12.305 / 10$, a compostagem constitui uma das tecnologias de gestão integrada de resíduo sólidos, utilizada para reciclagem de materiais orgânicos em um produto útil (BRASIL, 2010). A tecnologia de compostagem descentralizada apresenta vários benefícios que incluem o aumento da vida útil dos aterros sanitários e, por conseguinte, a diminuição dos gases que elevam o efeito estufa, higienização e estabilização, transformando a parcela orgânica, num produto final de valor agregado.

Silva et al. (2020b), em pesquisa realizada em resíduos sólidos orgânicos gerados em domicílios de um município de grande porte, constataram a contaminação desses resíduos por ovos de helmintos mesmo selecionados na fonte geradora. Ratificando que a destinação de resíduos sólidos orgânicos domiciliares sem tratamento, eleva as possibilidades de contaminação ambiental e, consequentemente, afeta a saúde humana, sobretudo, dos profissionais que lidam diretamente com esses resíduos, como evidenciaram Cavalcante et al. (2016), ao estudarem os riscos inerentes ao trabalho de catadores de materiais recicláveis formais e informais.

Há tecnologias que podem ser aplicadas ao tratamento de resíduos sólidos orgânicos domiciliares e que são eficientes, no que tange a transformação desses resíduos em compostos com características agronômicas viáveis ao uso agrícola (SILVA et al., 2020b). Todavia, há necessidade de tecnologias que sejam de baixo custo, fácil manuseio e adequadas às condições de infraestrutura da maioria da população brasileira.

Logo, o presente trabalho objetivou desenvolver e adaptar tecnologias para tratamento aeróbio de resíduos sólidos orgânicos domiciliares, de maneira a favorecer a implantação dessas tecnologias em domicílios e condomínios, contemplando os princípios de sustentabilidade e tecnologia social. 


\section{METODOLOGIA}

\section{Caracterização da pesquisa e da área de estudo}

A execução deste trabalho teve por base a pesquisa quantitativa, do tipo experimental, que consiste na elaboração de instrumentos para coleta de dados, submetidos a testes, como mencionam Marconi et al. (2011). A pesquisa foi desenvolvida no Laboratório do Grupo de Extensão e de Pesquisa em Gestão e Educação Ambiental (LabGGEA), no Departamento de Biologia, (UEPB), situado no Centro de Ciências Biológicas e da Saúde (CCBS), da Universidade Estadual da Paraíba (UEPB), Campus I, localizado em Campina Grande-PB, cuja população estimada é de 410.332 habitantes (BRASIL, 2017); um polo industrial e tecnológico regional, além de ser um importante centro universitário.

A coleta de dados foi realizada em cinco etapas: 1) Contato com as famílias; 2) Estruturação e montagem da área experimental; 3) Desenvolvimento e adaptação de tecnologias para tratamento biológico aeróbio de resíduos sólidos orgânicos domiciliares; 4) Coleta dos resíduos sólidos orgânicos nas residências; 5) Tratamentos dos resíduos sólidos orgânicos domiciliares.

Os resíduos sólidos orgânicos domiciliares utilizados nesta pesquisa foram coletados separados dos demais resíduos nas residências situadas no bairro Malvinas, em Campina Grande, estado da Paraíba, Brasil. A escolha do bairro decorreu do processo de sensibilização, formação e de mobilização de diferentes atores sociais que vem sendo aplicado na área em estudo (NASCIMENTO, 2015; ARAÚJO, 2018; SOUSA, 2018; ARAÚJO et al., 2019; SILVA et al., 2019; SILVA et al., 2020; 2020a; 2020b).

O processo de sensibilização antecedente a este trabalho foi de extrema importância para o andamento da pesquisa ora apresentada, tendo em vista o conhecimento das famílias sobre o tema (SILVA et al., 2019; SILVA et al., 2020; 2020a; 2020b). Destaca-se que o contato com as famílias foi feito de porta em porta com entrega de folhetos informativos sobre a pesquisa e resultados de demais trabalhos já realizados no bairro. Na oportunidade, foi respeitado o direito de participar ou não do projeto. Este momento ocorreu com ajuda de líderes comunitários e de uma Associação de catadores de materiais recicláveis que atua na área (GOMES, 2019).

A área experimental foi instalada ao lado do prédio das Três Marias, SITRADERO (Sistema de Tratamento Descentralizado Aeróbio de Resíduos Sólidos Orgânicos), localizado no Campus I, da UEPB, modificado por Araújo (2018). Este abrange uma área de $16 \mathrm{~m}^{2}$, e sua estrutura é constituída por madeira, lona e telas de proteção. Esta estrutura tem por finalidade impedir interferências diretas da chuva e insolação, bem como a presença de animais, sobretudo de grande porte.

Para determinar a quantidade de residências para coleta dos resíduos sólidos orgânicos, levou-se em consideração o número de casas que havia aderido à coleta seletiva no bairro Malvinas, totalizando 283 residências. A partir desse número foi adotada uma amostragem aleatória, composto por 63 famílias, correspondendo a uma amostra de $22,6 \%$. Ressalta-se que no final do processo de sensibilização, o total de famílias que praticava a coleta seletiva aumentou para 353, no entanto, o universo amostral deste trabalho persistiu (63 famílias). 


\section{Procedimentos para coleta de dados}

As coletas das amostras ocorreram durante um período de oito dias, seguindo-se o calendário da coleta do serviço público de limpeza urbana (terça-feira, quinta-feira e sábado). Foram coletados 330 kg de resíduos sólidos orgânicos. O total das amostras de resíduos sólidos orgânicos foi obtido a partir de quatro coletas.

Os resíduos sólidos orgânicos foram coletados em sacos plásticos cedidos pelos pesquisadores. A parcela orgânica era separada dos demais resíduos e encaminhada ao SITRADERO. Neste local, os resíduos sólidos orgânicos foram pesados e armazenados durante oito dias que corresponderam ao período de coletas.

Os resíduos sólidos orgânicos domiciliares coletados foram bastante heterogêneos, desde cascas de frutas, frutas, legumes, restos de comida, ossos, pães, pó de café, folhas, palha e sabugos de milho e cascas de ovos. Após a caracterização, estes materiais foram triturados, visando reduzir o tamanho de suas partículas e obter granulometria favorável à ação dos organismos responsáveis pela degradação da matéria orgânica, sobretudo, dos microrganismos.

Após as etapas de sensibilização, montagem da área experimental, coleta dos resíduos sólidos orgânicos nas residências, seguiu-se com o desenvolvimento e adaptação das tecnologias para tratamento biológico aeróbio de resíduos orgânicos domiciliares, também denominados de sistemas de tratamento biológico aeróbio de resíduos sólidos orgânicos domiciliares (SITRADEROMóveL) (Figura 1).

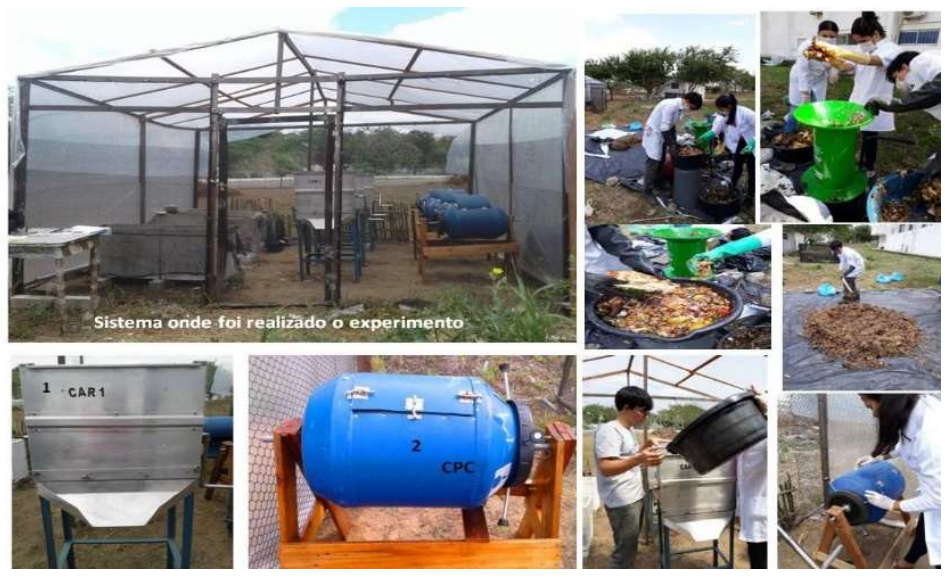

Figura 1: Sistema de Tratamento Biológico de Resíduos Sólidos Orgânicos Domiciliares- SITRADERO móvel, composteiras CAR e CPC e trituração dos resíduos sólidos orgânicos para montagem do experimento.

1- CAR- Composteira de alumínio e inox retangular 2- CPC- Composteira de polietileno cilíndrica

As tecnologias em estudo foram constituídas por dois modelos de composteiras móveis em triplicata: composteira de alumínio e inox retangular - CAR (NASCIMENTO, 2015; ARAÙJO, 2018; ARAÚJO et al., 2019; GOMES, 2019; SILVA et al., 2019) e composteira de polietileno cilíndrica-CPC (GOMES, 2019), como pode ser visualizado por meio da Figura 1.

A partir dos testes realizados com outros modelos de composteiras, foram identificados entraves em relação ao reviramento do substrato: desprendimento de esforço físico excessivo e aumento do tempo de estabilização dos resíduos sólidos orgânicos. Mediante a problemática, somada aos princípios da 
sustentabilidade e de tecnologia social, foram estudados dois modelos de composteiras que atendessem a esse anseio e possibilitassem a aplicação da compostagem em pequena escala e de forma descentralizada e apropriadas às residências ou condomínios residenciais verticais e horizontais.

Neste sentido, o modelo de composteira CAR desenvolvido por Nascimento (2015) e adaptado por Araújo (2018) e Gomes (2019), apresentam no seu interior uma hélice acoplada a uma manivela que ao girar permite a oxigenação, o revolvimento e a homogeneização do material (figura 2). Por outro lado, o modelo de composteira CPC foi desenvolvido com o diferencial, além do material empregado (polietileno) e da configuração (cilíndrica), a aplicação de uma estrutura que facilita a oxigenação, o revolvimento e a homogeneização, roda leme, proporcionando aos operadores, menor desprendimento de esforço físico (figura 3).

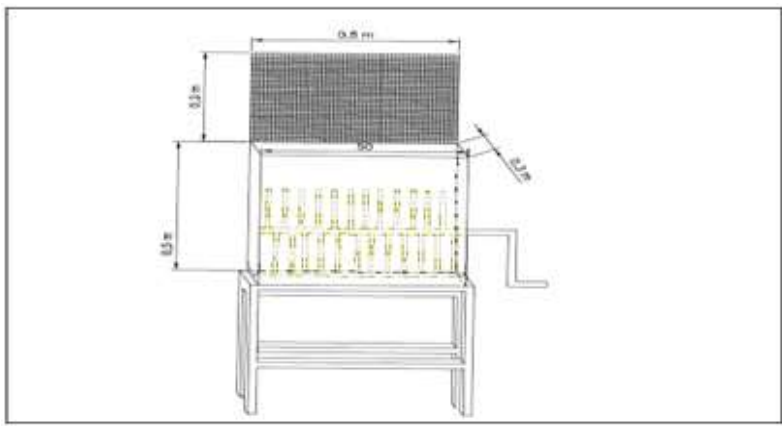

Figura 2: Desenho esquemático da composteira de alumino e inox retangular (CAR), com modificações na parte interna da manivela. Fonte: Nascimento (2015), adaptado por Gomes (2019).

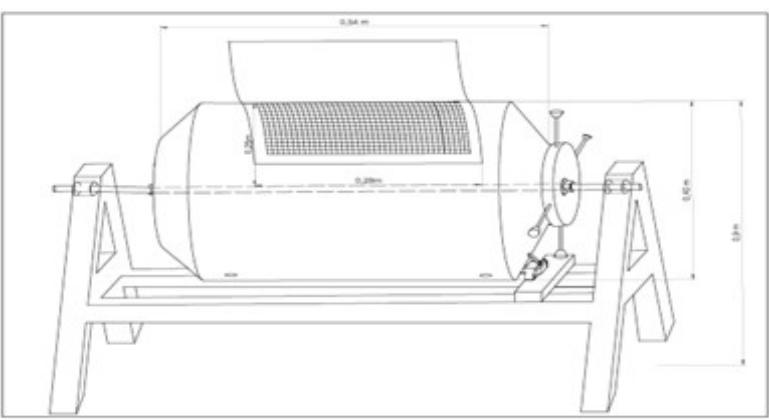

Figura 3: Desenho esquemático da composteira cilíndrica em polietileno (CPC). Fonte: Gomes (2018).

Os tratamentos foram aplicados em triplicata: $\mathrm{CAR}_{1}, \mathrm{CAR}_{2}, \mathrm{CAR}_{3} ; \mathrm{CPC}_{1} \mathrm{CPC}_{2}$ e $\mathrm{CPC}_{3}$ (Quadro 1). Cada composteira foi alimentada com $26,6 \mathrm{~kg}$ de substratos triturados (Figura 1). Desse total, 80\% eram resíduos sólidos orgânicos domiciliares e $20 \%$ de estruturantes. Estes foram compostos por folhas, adubo tipo farelo e rejeitos (material orgânico que não foi totalmente degradado em outros experimentos). As dimensões das composteiras estão apresentadas no Quadro 1.

Quadro 1: Características dos modelos de tecnologias para tratamento biológico aeróbio de resíduos sólidos orgânicos domiciliares.

\begin{tabular}{|c|c|c|c|c|c|c|c|}
\hline \multirow{2}{*}{ Siglas } & \multirow{2}{*}{ Composteiras } & \multicolumn{3}{|c|}{ Dimensões (m) } & \multirow{2}{*}{ Volume $\left(\mathrm{m}^{3}\right)$} & \multirow{2}{*}{$\begin{array}{l}\text { Capacidade de carga } \\
\text { (kg) }\end{array}$} & \multirow[t]{2}{*}{ Subsistemas } \\
\hline & & $\mathbf{L}$ & c & $\mathbf{h}$ & & & \\
\hline \multirow{4}{*}{ CAR } & & & & & & & $\mathrm{CAR}_{1}$ \\
\hline & Aço inoxidável retangular & 0,30 & 0,50 & 0,50 & $0,075 \mathrm{~m}^{3}$ & 30 & $\mathrm{CAR}_{2}$ \\
\hline & & & & & & & $\mathrm{CAR}_{3}$ \\
\hline & & & & & & & $\mathrm{CPC}_{1}$ \\
\hline \multirow[t]{2}{*}{ CPC } & Polietileno cilíndrico & 0,30 & 0,54 & 0,40 & $0,04 \mathrm{~m}^{3}$ & 30 & $\mathrm{CPC}_{2}$ \\
\hline & & & & & & & $\mathrm{CPC}_{3}$ \\
\hline
\end{tabular}

L- largura c- comprimento h-altura

Análise Física, Química e Biológica dos resíduos sólidos orgânicos domiciliares, e composto final

As análises físicas, químicas e biológicas dos resíduos sólidos orgânicos domiciliares e do composto final foram realizadas no LabGGEA e no Laboratório de Microbiologia do Departamento de Biologia (UEPB), ambos situados no Centro de Ciências Biológicas e da Saúde (CCBS), da UEPB, Campus I e no laboratório do 
Setor de Ciências do Solo da Universidade Federal da Paraíba, na cidade de Areia-PB. As análises estudadas estão descritas no quadro 2.

Quadro 2: Caracterização físico-química e biológica dos resíduos sólidos orgânicos domiciliares, substratos e compostos.

\begin{tabular}{|c|c|c|c|c|}
\hline \multicolumn{2}{|c|}{ Parâmetros } & \multirow{3}{*}{$\begin{array}{l}\text { Frequência } \\
\text { Diariamente até 15ㅇa dia } \\
\text { Semanal }\end{array}$} & \multirow{3}{*}{$\begin{array}{l}\text { Método Utilizado } \\
\text { Aferição por termômetro mercúrio }\end{array}$} & \multirow{3}{*}{$\begin{array}{l}\text { Fonte } \\
\text { APHA et al. (2005) }\end{array}$} \\
\hline \multirow{3}{*}{$\frac{8}{\frac{3}{4}}$} & \multirow{2}{*}{ Temperatura $\left({ }^{\circ} \mathrm{C}\right)$} & & & \\
\hline & & & & \\
\hline & Teor de umidade (\%) & Semanal & Gravimétrico & Goldin (1987) \\
\hline \multirow{6}{*}{$\frac{8}{. \frac{8}{\varepsilon}}$} & $\mathrm{pH}$ (Unidade) & Semanal & Potenciométrico & APHA et al. (2005) \\
\hline & Carbono Orgânico Total (\%COT) & Inicial e Final & Kiehl (1998) 1,8xSTV & Goldin (1987) \\
\hline & Sólidos Totais Voláteis (\%ST) & Semanal & Gravimétrico & Silva (2008) \\
\hline & Potássio (\%ST) & Inicial e Final & Fotometria de chama & Okumura et al. (2004) \\
\hline & Nitrogênio total (\%NTK) & Inicial e Final & Método Kjeldhal & Tedesco et al. (1995) \\
\hline & Fósforo Total (\%ST) & Inicial e Final & $\begin{array}{l}\text { Espectrofotométrico com ácido } \\
\text { ascórbico }\end{array}$ & Tedesco et al. (1995) \\
\hline$\frac{\circ}{\circ}$ & Ovos de Helmintos (ovos/gST) & Inicial e Final & $\begin{array}{l}\text { Meyer et al. (1978) adaptado por Silva } \\
(2008)\end{array}$ & Silva (2008) \\
\hline
\end{tabular}

\section{RESULTADOS E DISCUSSÃO}

\section{Desenvolvimento e adaptação de tecnologias de tratamento aeróbio de resíduos sólidos orgânicos domiciliares}

Os resíduos sólidos orgânicos domiciliares constituem uma fonte valiosa de nutrientes, podendo retornar ao ciclo produtivo quando submetido a tratamento; do contrário, pode constituir uma fonte potencial danosa ao meio ambiente e a saúde pública.

O tratamento da parcela orgânica em composteiras móveis atende aos anseios do público envolvido neste trabalho e aos princípios de sustentabilidade e tecnologia social. Estudando-se os modelos de composteiras desenvolvidos por Nascimento (2015) e Araújo (2018) foram verificadas limitações referentes ao custo de confecção e ao reviramento do substrato que demandavam o uso de instrumentos agrícolas, tais como: pás e espátulas e considerável esforço físico. Visando superar as limitações mencionadas, foi estudado e confeccionado um novo modelo de composteira (CPC), com tambor de polietileno, de $40 \mathrm{~L}$, com tampa negra, com uma base feita em madeira e uma roda de leme. A roda em leme auxilia no revolvimento do substrato com o desprendimento de menor esforço físico, resultando num modelo de composteira cilíndrica de polietileno (CPC) (Figuras 3, 4 e 5).

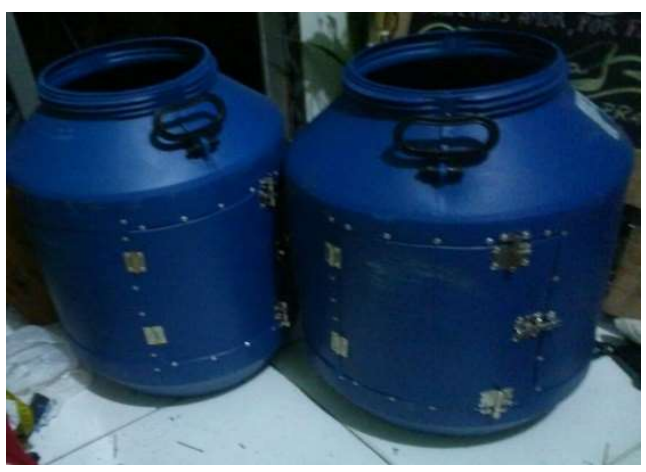

Figura 4: Material adotado para confecção do modelo de composteira móvel de polietileno com configuração cilíndrica.

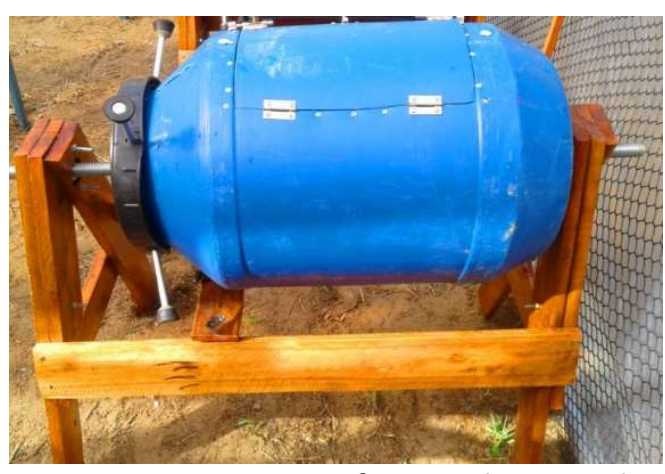

Figura 5: Composteiras confeccionadas em polietino com configuração cilíndrica (CPC).

Para a confecção desse modelo foram realizadas pesquisas de mercado para levantamento dos 
valores dos materiais e disponibilidade. A partir do conhecimento dos valores, foi feita a escolha do material. A configuração cilíndrica permite que os resíduos sólidos orgânicos se distribuam uniformemente, sem a formação de regiões isoladas, propiciando o maior contato entre as partículas no momento do reviramento.

A adoção da roda de leme constituiu um diferencial, comparando-se aos modelos propostos por Nascimento (2015) e Araújo (2018), por facilitar o reviramento do substrato sem contato com instrumentos agrícolas, o que evita contaminação e, por demandar menor esforço físico dos operadores, favorecendo, desse modo, a sua adoção pelos moradores do bairro que sempre usaram este aspecto como empecilho para realizar a compostagem em suas residências.

Para diminuir o esforço físico e facilitar o revolvimento, foram utilizados dois rolamentos nas laterais do suporte ligados a uma barra roscada. O movimento é auxiliado por roda leme (figura 6). Para confecção do leme, foi utilizada a tampa do tambor e nele foram acoplados quatro parafusos sextavados, zincados, de $15 \mathrm{~cm}$, e borrachas na parte superior de cada parafuso para dar suporte no momento do reviramento.

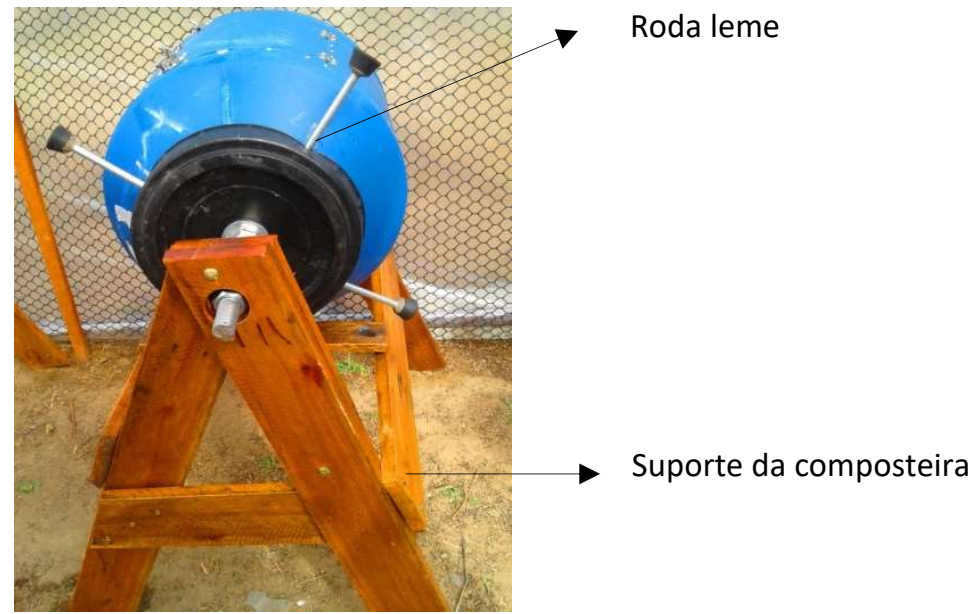

Figura 6: Modelo da roda leme adotada para reviramento do substrato em CPC.

A composteira de polietileno cilíndrica apresenta ainda uma porta na parte superior que conta com três dobradiças (figura 7) que permitem abrir e fechar no momento do reviramento. Foi confeccionada uma tela de polietileno removível que fica acoplada à porta para evitar a entrada de organismos indesejáveis e a perda de umidade, assim como, para possibilitar a entrada de ar (figura 8). Esse modelo também conta com um sistema de trava localizada na parte inferior para garantir a sua estabilidade e dois orifícios na parte superior para saída de gás e dois orifícios na parte inferior para saída de chorume, caso ocorra produção deste líquido, fato não desejável em sistema de tratamento aeróbio de resíduos sólidos orgânicos. O modelo CPC é constituído por um compartimento, medindo 0,54 m de comprimento, 0,30 m de largura e 0,40 m de altura, com capacidade volumétrica de $0,04 \mathrm{~m}^{3}$ ou $30 \mathrm{~kg}$.

Para a montagem do suporte da composteira CPC foi utilizado pallet de madeira, por ser um material de baixo custo e fácil acesso. Levou-se em consideração também as questões ambientais, contribuindo para a reutilização desse tipo de material. Além de pallets, foi utilizada madeira de eucalipto, a qual apresenta vantagens, comparando-se a outros tipos de madeiras, por causar menor dano ambiental e possuir boa qualidade e durabilidade. 


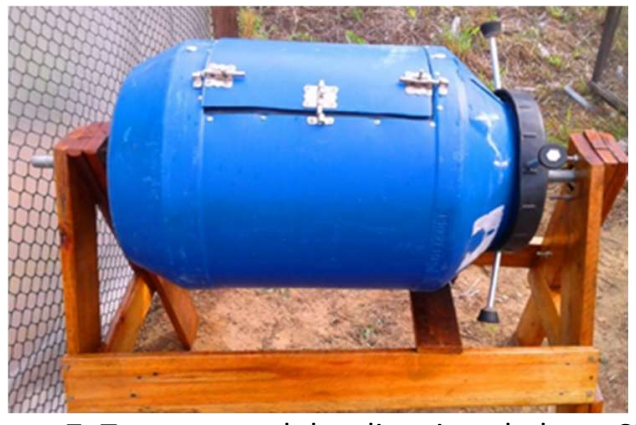

Figura 7: Tampa com dobradiças instalada na CPC com roda de leme para reviramento.

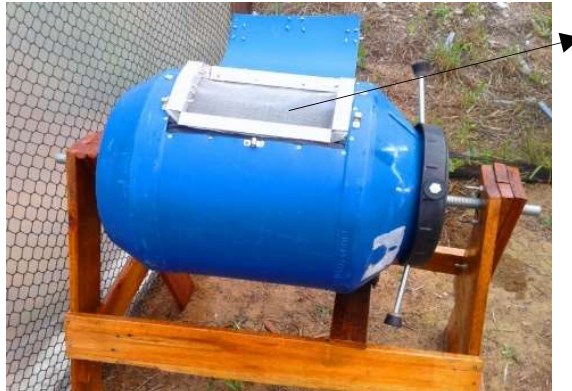

Cobertura em

polietileno para aeração

O modelo de composteiras em alumínio e aço inoxidável retangular (CAR), desenvolvido por Nascimento (2015), apresentava limitações que impediam o reviramento mecânico dos resíduos sólidos orgânicos em tratamento, sendo necessário o auxílio de uma espátula (figura 9). Araújo (2018) utilizou o mesmo modelo de composteira, com adaptações na parte interna, a exemplo de uma hélice acoplada a uma manivela, no entanto, não obteve o resultado esperado (figura 10), permanecendo o entrave em relação ao reviramento.

Neste trabalho deu-se atenção a essa problemática, com adoção de mudança na estrutura interna da composteira CAR (Figura 11). A alteração foi efetivada nas hélices que ficaram em diferentes posições, de maneira que à medida que adentrasse no material, criassem áreas para circulação do ar e facilitassem o revolvimento.

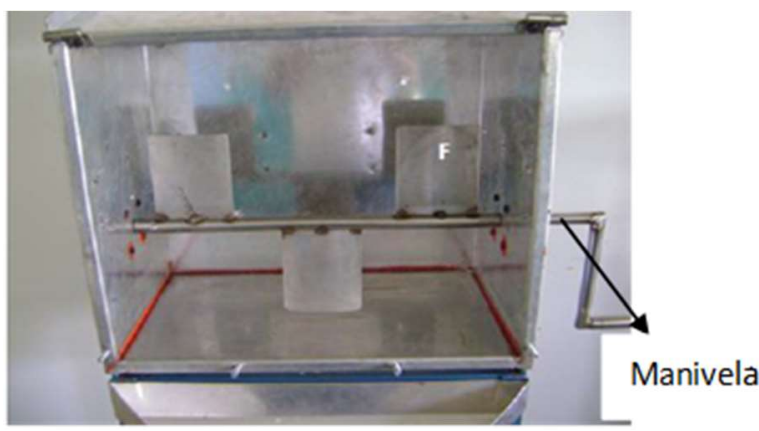

Figura 9: Estruturação da parte interna da composteira CAR que corresponde à manivela. Fonte: Nascimento (2015).

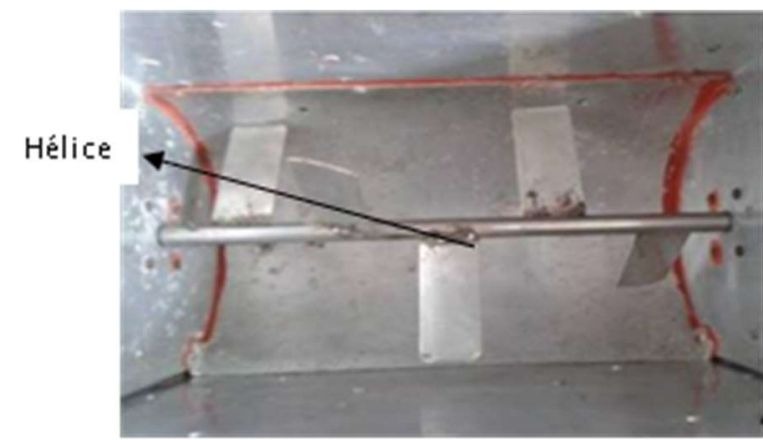

Figura 10: Adaptação aplicada na parte interna da Composteira CAR. Fonte: Araújo (2018).

Aumento do número de pás em sentido diferentes, configurando uma hélice.

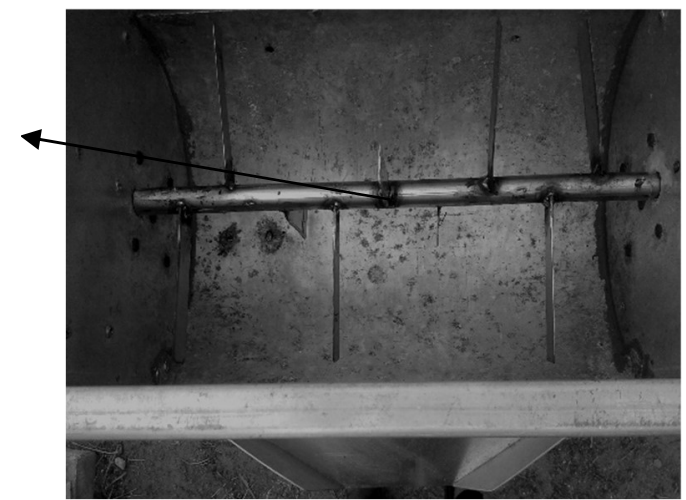

Figura 11: Adaptações aplicadas à estrutura interna da composteira CAR. Fonte: Araújo (2018) adaptado por Gomes (2019).

O monitoramento do sistema formado pelos dois tipos de composteiras (CPC e CAR) de forma 
criteriosa foi essencial ao funcionamento adequado desses sistemas, de maneira que ao final do processo foram obtidos compostos higienizados e estabilizados (Tabela 1). Compreende-se que ações da presente pesquisa foram fundamentais ao desenvolvimento de tecnologia de caráter social e contributiva aos objetivos da gestão integrada de resíduos sólidos.

Sabe-se que a gestão integrada de resíduos sólidos não constitui uma única solução, mas corresponde a um conjunto de alternativas centradas nos princípios da sustentabilidade e de responsabilidade compartilhada: coleta seletiva na fonte geradora, inserção socioeconômica dos catadores de materiais recicláveis, tratamento da parcela orgânica e disposição final de rejeitos em aterro sanitário (BRASIL, 2010; BESEN, 2012; SILVA, 2020; SILVA et al., 2020, 2020a, 2020b).

As tecnologias de tratamento de resíduos sólidos orgânicos móveis e centrados nos princípios da tecnologia social constituem um atributo imprescindível à saúde ambiental e humana, ao considerar que no Brasil mais de 50\% dos resíduos sólidos urbanos são orgânicos (BRASIL, 2017) e que estes expressam riscos de significativa contaminação e de poluição ambiental (SILVA et al., 2020b).

Por meio de tecnologias de tratamento biológico aeróbio, é possível transformar problema em solução (SILVA, 2020) e constituir um composto com características ideais às diversas atividades agrícolas.

\section{Características Físicas, Químicas e Biológicas dos Resíduos Sólidos Orgânicos Domiciliares e dos compostos resultantes do tratamento biológico aeróbio aplicado por meio das composteiras CAR e CPC}

Os resíduos sólidos orgânicos domiciliares apresentaram características físicas, químicas e biológicas (Tabela 1) que por um lado, aferem uma fonte de nutrientes ideais aos organismos autotróficos, por outro, constituem uma fonte potencial de poluição e contaminação. Características que demandam a separação na fonte geradora e o encaminhamento ao devido tratamento, no sentido de evitar ou mitigar os efeitos adversos sobre a sua ambiental e humana.

Tabela 1: Caracterização física, química e sanitária dos resíduos sólidos orgânicos domiciliares submetidos ao tratamento aeróbio biológico.

\begin{tabular}{ll}
\hline Parâmetros & Valores \\
\hline Teor de umidade (\%) & 72 \\
STV (\%ST) & 83 \\
pH & 5,2 \\
Ovos helmintos (ovos/gST) & 4,1 \\
COT (\%ST) & 40 \\
N (\%ST) & 1 \\
P (\%ST) & 0,02 \\
K (\%ST) & 0,02
\end{tabular}

STV: sólidos totais voláteis COT: Carbono Orgânico Total N: Nitrogênio; P: Fósforo; K: Potássio.

De acordo com os dados apresentados na Tabela 1, os parâmetros pH $(5,2)$, teor de umidade $(72 \%)$, sólidos totais voláteis ( $83 \% \mathrm{ST}$ ) e ovos de helmintos (4,1 ovos/gST) ratificaram a necessidade de tratar estes resíduos. O teor de umidade, a expressiva quantidade de sólidos totais voláteis e $\mathrm{pH}$ ácido favorecem as atividades de uma diversidade de organismos, dentre os quais, os patógenos. Nessas condições, sobressaemse os microrganismos anaeróbios, resultando na geração de subprodutos indesejáveis no contexto de gestão ambiental e de sustentabilidade, chorume e gases de efeito estufa (GEE). A quantidade de ovos de helmintos 
atina para o alto risco de contaminação biológica que implicará prejuízos à saúde humana.

As características físicas e químicas desses resíduos (Tabelas 1 e 2), no entanto, apontaram para viabilidade de tratamento biológico aeróbio, cujo princípio básico, conforme Silva (2008) é propiciar condições favoráveis aos organismos autóctones e desfavoráveis aos patógenos. Os organismos autóctones, conforme observação direta aplicada durante o monitoramento diário e por meio das análises (Tabela 2), ao desempenharem o seu nicho ecológico, modificaram o ambiente, sobretudo em relação aos níveis de temperatura (ambiente-mesófila-termófila-mesófila-ambiente) e transformaram matéria orgânica em inorgânica, tornando o sistema (ambiente) inóspito aos organismos heterotróficos patógenos, dentre esses, helmintos, na fase de ovo (Tabelas 1 a 3). Dessa interação, resultaram compostos com características viáveis ao uso agrícola (Tabela 3).

Tabela 2: Características dos resíduos sólidos orgânicos domiciliares e dos substratos ao longo do tratamento biológico aeróbio aplicado por meio das Composteiras CAR e CPC

\begin{tabular}{|c|c|c|c|c|c|c|c|c|c|}
\hline \multirow{2}{*}{\multicolumn{2}{|c|}{ Tempo }} & \multicolumn{8}{|c|}{ Parâmetros } \\
\hline & & \multicolumn{2}{|c|}{ Teor de Umidade (\%) } & \multicolumn{2}{|c|}{ STV (\%ST) } & \multicolumn{2}{|l|}{$\mathrm{pH}$} & \multicolumn{2}{|c|}{ Ovos de Helmintos (ovos viáveis/gST) } \\
\hline Semana & Dia & CAR & CPC & CAR & CPC & CAR & $\mathrm{CPC}$ & CAR & CPC \\
\hline $1 \underline{a}$ & 7 & 67 & 68 & 78 & 74 & 5 & 6 & 5 & 5 \\
\hline $2 \underline{a}$ & 14 & 65 & 69 & 67 & 65 & 8 & 8 & 2 & 6 \\
\hline 3 a & 21 & 47 & 65 & 54 & 60 & 8 & 9 & 3 & 3 \\
\hline $4 \underline{a}$ & 28 & 42 & 46 & 64 & 52 & 8 & 8 & 2 & 3 \\
\hline $5 \underline{a}$ & 35 & 32 & 52 & 55 & 56 & 9 & 9 & 2 & 4 \\
\hline $6 \underline{a}$ & 42 & 37 & 45 & 53 & 48 & 9 & 8 & 2 & 1 \\
\hline $7 \underline{a}$ & 49 & 30 & 36 & 55 & 40 & 9 & 9 & 1 & 1 \\
\hline $8^{a}$ & 56 & 19 & 30 & 58 & 57 & 9 & 9 & 0,4 & 0,4 \\
\hline 9a & 63 & 18 & 28 & 53 & 46 & 9 & 9 & 0,3 & 0 \\
\hline 10 a & 70 & 13 & - & 54 & - & 9 & - & 0,1 & - \\
\hline 11 a & 77 & 19 & - & 58 & - & 9 & - & 0 & - \\
\hline
\end{tabular}

Em consonância com a Instrução Normativa n²5 de 23 de julho de 2009 (BRASIL, 2009), os compostos resultantes são classificados como fertilizantes orgânicos classe $C$ e atendem à faixa indicativa pela Instrução Normativa n. 25 de 23 de julho de 2009 (BRASIL, 2009) e n. 7 de 12 de abril de 2016 (Tabela 3).

Tabela 3: Características dos resíduos sólidos orgânicos domiciliares e dos respectivos compostos resultantes do tratamento biológico aeróbio aplicado por meio das composteiras CAR e CPC.

\begin{tabular}{|c|c|c|c|c|c|}
\hline \multirow{4}{*}{ Parâmetros } & \multirow{4}{*}{$\begin{array}{l}\text { Resíduos Sólidos o } \\
\text { Orgânicos Domiciliares }\end{array}$} & \multicolumn{2}{|c|}{ Composto Resultant } & \multirow{2}{*}{\multicolumn{2}{|c|}{ Instrução Normativa }} \\
\hline & & \multirow{3}{*}{ CAR } & \multirow{3}{*}{ CPC } & & \\
\hline & & & & & \\
\hline & & & & Faixa indicativa & Fonte \\
\hline Umidade (\%) & 72 & 19 & 30 & $<50$ & Brasil $(2009)^{1}$ \\
\hline STV (\%ST) & 83 & 48 & 46 & $<50$ & Brasil $(2009)^{1}$ \\
\hline $\mathrm{pH}$ & 5,2 & 8,7 & 8,8 & $>6,5$ & Brasil $(2009)^{1}$ \\
\hline Helmintos (ovos/gST) & 4,1 & 0,0 & 0,0 & 1 & Brasil $(2016)^{2}$ \\
\hline COT (\%ST) & 40 & 26 & 25 & $>15$ & Brasil (2009) ${ }^{1}$ \\
\hline $\mathrm{N}(\% \mathrm{ST})$ & 1 & 0,04 & 0,04 & $>0,05$ & Brasil $(2009)^{1}$ \\
\hline $\mathrm{P}(\% \mathrm{ST})$ & 0,02 & 0,01 & 0,01 & $>1$ & Brasil (2009) ${ }^{1}$ \\
\hline $\mathrm{K}(\% \mathrm{ST})$ & 0,02 & 0,03 & 0,03 & $>1$ & Brasil $(2009)^{1}$ \\
\hline
\end{tabular}

1- Instrução Normativa $n^{\circ} 25$ de 23 de julho de 2009 (BRASIL, 2009). 2- Instrução Normativa n 7 de abril de 2016 (BRASIL, 2016).

Analisando-se os dados expostos nas Tabelas 1, 2 e 3, constata-se que as composteiras confeccionadas com materiais distintos (CAR- aço inox e alumínio e CPC- polietileno), configurações 
diferentes (retangular e cilíndrico) e acessórios díspares para homogeneização e reviramento (manivela e roda de leme) apresentaram comportamentos diversificados para composição física, química e biológica e para o tempo de estabilização da matéria orgânica (Tabela 1 a 3).

Em termos de comparação, o tempo médio de estabilização nas composteiras CPC (63 dias) foi inferior ao tempo médio verificado nas composteiras CAR (79 dias). As médias registradas para o tempo de estabilização são inferiores as médias citadas pela maioria dos trabalhos publicada na área objeto de estudo, 90 a 120 dias (SILVA, 2008; SILVA et al., 2011; SILVA et al., 2014; NASCIMENTO, 2015; ARAÚJO, 2018; ARAÚJO et al., 2019). Expressando significativa redução do tempo para o tratamento dos resíduos sólidos orgânicos domiciliares. Atribui-se esta diminuição do tempo para estabilização à trituração dos resíduos sólidos orgânicos domiciliares, a configuração e cobertura do SITRADERO e ao teor de umidade inicial (72\%). Fatores que favoreceram a ação dos organismos aeróbios autóctones, degradando a matéria orgânica, consequentemente, aumentando os níveis de temperatura, os quais são essenciais à destruição e/ou inviabilização de ovos de helmintos. Destaca-se que as composteiras de polietileno cilíndricas, CPC, tiveram melhor otimização do tempo para estabilização, possivelmente, devido a sua configuração e a aeração aplicada com a utilização da roda de leme.

Os dois modelos de composteiras estudados neste trabalho atingiram os principais objetivos do tratamento biológico de resíduos sólidos orgânicos, estabilização e sanitização e mostraram-se ideais ao uso em escala domiciliar, seja em residências ou em condomínios verticais e horizontais.

\section{CONCLUSÕES}

De acordo com o cenário analisado, as tecnologias de tratamento de resíduos sólidos orgânicos domiciliares apresentaram comportamento diferenciado em relação à diversidade de organismos e em relação aos parâmetros físicos e químicos, verificando-se que o modelo de composteira influencia de forma direta na atividade metabólica dos organismos que degradam a matéria orgânica.

Os modelos adotados para o tratamento de resíduos sólidos orgânicos domiciliares favoreceram o alcance dos objetivos deste tipo de tratamento: estabilização e higienização da parcela orgânica. O modelo CPC mostrou-se mais eficiente no que tange a otimização do tempo de estabilização (63 dias), comparandose com o modelo CAR (79 dias).

O modelo CPC desempenhou melhor as suas funções e sua configuração possibilitou o revolvimento do material sem desprender maiores esforços. Os materiais empregados para confecção do modelo CPC são de baixo custo e há disponibilidade no mercado local. Ressalta-se, no entanto, que os dois modelos são viáveis e podem ser adotadas pelas famílias em residências ou em condomínios residenciais verticais e horizontais, cumprindo-se os princípios da sustentabilidade e de tecnologia social.

Portanto, os modelos de composteiras estudados foram viáveis ao alcance dos objetivos esperados para o tratamento biológico aeróbio de resíduos sólidos orgânicos domiciliares: estabilização e higienização da parcela orgânica com espaço de tempo médio inferior a 80 dias. Ao considerar o tempo de estabilização, facilidade de operação, aplicação em pequena escala e a qualidade do composto final, o modelo de CPC 
mostrou-se mais eficiente.

\section{REFERÊNCIAS}

APHA; AWWA; WEF. American Public Health Association; American Water Works Association; World Economic Forum. Standard Methods for examination of water and wastewater. $21 \mathrm{ed}$. Washington: APHA, 2005.

ARAÚJO, E. C. S.. Organismos que participam das diferentes fases do tratamento aeróbio de resíduos sólidos orgânicos domiciliares. Dissertação (Mestrado em Ciência e Tecnologia Ambiental) - Universidade Estadual da Paraíba, Campina Grande, 2018.

ARAÚJO, E. S. A.; SILVA, M. M. P.; SILVA, A. V.; LEITE, V. D.; BARROS, A. T.. Diversidade e Funções de Mesoinvertebrados no Tratamento Aeróbio de Resíduos Sólidos Orgânicos Domiciliares em Sistemas Descentralizados, Campina Grande-PB. In: CONGRESSO BRASILEIRO DE ENGENHARIA SANITÁRIA E AMBIENTAL, 30. Anais. Natal: ABES, 2019.

\section{BRASIL. Constituição da República Federativa do Brasil} 1988. Brasília: DOU, 1988.

BRASIL. Fundação Nacional de Saúde. Manual de saneamento. 3 ed. Brasília: Fundação Nacional de Saúde, 2007.

BRASIL. Instrução Normativa n. $\mathbf{2 5}$ de $\mathbf{2 3}$ de julho de 2009. Aprova as normas sobre as especificações e as garantias, as tolerâncias, o registro, a embalagem e a rotulagem dos fertilizantes orgânicos simples, mistos, compostos, organominerais e biofertilizantes destinados à agricultura. Brasília: Ministério de Agricultura, Pecuária e Abastecimento, 2009.

BRASIL. Política Nacional de Resíduos sólidos. Lei 12.305/2010. Brasília: DOI, 2010.

BRASIL. Ministério do Meio Ambiente. Compostagem doméstica comunitária e institucional de resíduos orgânicos: manual de orientação. Brasília: MMA, 2017.

BRASIL. Instrução Normativa n. 7 de $\mathbf{1 2}$ de abril de 2016. Limites máximos de contaminantes admitidos em substrato para plantas Brasília: Ministério de Agricultura, Pecuária e Abastecimento, 2016.

CASTALDI, P.; GARAU, G.; MELIS, P.. Maturity assessment of compost from municipal solid waste through the study of enzyme activities and water-soluble fractions. Waste Manage., Kidlington, v.28, n.3, p.534- 540, 2008.

CAMPITELLI, P.. Calidad de compost y vermicompuestos para su uso como enmiendas orgánicas en suelos agrícolas. Tese (Doutorado) - Universidade Nacional de Córdoba, Córdoba, 2010.

CAVALCANTE, L. S.; SILVA, M. M. P.; LIMA, V. L. A.. Riscos inerentes ao ambiente de trabalho de catadores de materiais recicláveis formais e informais. Revista IberoAmericana de Ciências Ambientais, v.7, n.2, p.111-125, 2016.

CHANDNA, P.; NAIN, L.; SINGH, S.; KUHAD, R. C.. Assessment of bacterial diversity during composting of agricultural by products. BMC Microbiology, v.13, n.99, p.1-14, 2013.

EJAZ, N.; AKHTAR, N.; NISAR, H.; NAEEM, U. A.. Environmental impacts of improper solid waste management in developing countries: a case study of Rawalpindi City. WIT Transactions on Ecology and the Environment, v.142, p.379-387, 2010.

GAMA, A. M. C. F.; COSTA, V. C. B.; FIRMO, A. B. L.; JUCÁ, J. F. T.. Estudo das emissões de GEE da disposição de resíduos sólidos na região metropolitana do Recife. Revista IberoAmericana de Ciências Ambientais, v.10, n.6, p.163-177, 2019.

GOLDIN, A.. Reassessing the use of loss-on-ignition for estimating organic matter content in noncalcareous soils. Commun. Soil Science. Plant, v.18, n.9, p.1111-1116, 1987.

GOMES, I.. Comportamento de Enterobactérias em Sistemas de Tratamento Aeróbio Descentralizado de Resíduos Sólidos Orgânicos Domiciliares. Dissertação (Mestrado em Ciência e Tecnologia Ambiental) Universidade Estadual da Paraíba, Campina Grande, 2019.

HASSEN, A; BELGUITH, K; JEDIDI, N; CHERIFIF, A; CHERIF, M; BOUDABOUS, A.. Microbial characterization during composting of municipal solid waste. Bioreource Techonology, v.80, n.3, p.217-225 2001. DOI: https://doi.org/10.1016/S0960-8524(01)00065-7

HAMILTON, S. F.; THOMAS, W. P.; SUNDING, D.; ZILBERMAN, D.. Environmental policy with collective waste disposal. Journal of Environmental Economics and Management, v.66, p.337-346, 2013.

HECK, K.; MARCO, E. G.; HAHN, A. B. B.; KLUGE, M.; SPILKI, F. R.; SAND, S. T. V. D.. Temperatura de degradação de resíduos em processo de compostagem e qualidade microbiológica do composto final. Revista Brasileira de Engenharia Agrícola e Ambiental, Campina Grande, v.17, n.1, p.54-59, 2013.

MARCONI, M. A.; LAKATOS, E. M.. Metodologia Científica. 6 ed. São Paulo: Atlas S.A., 2011.

MEYER, K. B.; MILLER, K. D.; KANESHIRO, S.. Recovery of ascaris eggs from sludge. Journal of Parasitology, v.64, n.2, p.380-383, 1978.

MISHRA, R. V.; ROY, R. N.; HIRAOKA, H.. On-farm composting methods. Roma: Food and Agriculture Organization of the United Nations, 2003.

MARGARITIS, M.; PSARRAS, K.; PANARETOU, V.; THANOS, A. G.; MALAMIS, D.; SOTIROPOULOS, A.. Improvement of home composting process of food waste using different minerals. Waste Management, v.73, 2018. DOI: http://doi.org/10.1016/j.wasman.2017.12.009

NASCIMENTO, C. R.. Sistema de tratamento descentralizado de resíduos sólidos orgânicos no bairro Malvinas, Campina 
Grande-PB. Dissertação (Mestrado em Ciências e Tecnologia Ambiental) - Universidade Estadual da Paraíba, Campina Grande, 2015.

OKUMURA, F.; CAVALHEIRO, E. T. G.; NOBREGA, J. A.. Experimentos simples usando fotometria de chama para ensino de princípios de espectrometria atômica em cursos de química analítica. Química Nova, v.27, n.5, p.832, 2004 DOI: https://doi.org/10.1590/s0100-40422004000500026

OLIVEIRA, I. S.; SILVA, M. M. P.. Educação Ambiental em Comunidade Eclesial de Base na Cidade de Campina Grande: contribuição para o processo de Mobilização social. Revista Eletrônica do Mestrado em Educação Ambiental, v.18, 2007. DOI: https://doi.org/10.14295/remea.v18i0.3331

SILVA, M. M. P.. Manual teórico metodológico de Educação Ambiental. Campina Grande: Maxgraf Ltda., 2016.

SILVA, M. M. P. Manual de educação ambiental: uma contribuição à formação de agentes multiplicadores em educação ambiental. Curitiba: Appris, 2020.

SILVA, M. M. P.; SOUSA, J. T.; CEBALLOS, B. S. O.; FEITOSA, W. B. S.; LEITE, V. D.. Avaliação sanitária de resíduos sólidos orgânicos domiciliares em municípios do semiárido paraibano. Revista Caatinga, Mossoró, v.23, n.2, p.87-92, 2010.

SILVA, M. M. P.; OLIVEIRA, A. G.; LEITE, V. D.; SOARES, L. M. P.; OLIVEIRA, S. C.. Avaliação de sistema de tratamento descentralizado de resíduos sólidos orgânicos domiciliares em Campina Grande-PB. In: CONGRESSO BRASILEIRO DE ENGENHARIA SANITÁRIA E AMBIENTAL. 26. Anais. Porto Alegre: ABES, 2011.

SILVA, M. M. M.; SOUZA, D. M.; SILVA, P. A.; JUSTINO, E. D.; RIBEIRO, V. V.. Influência de cobertura no desempenho de sistema de tratamento descentralizado de resíduos sólidos orgânicos domiciliares implantado na zona urbana, em Campina Grande-PB. In: SIMPÓSIO ÍTALO-BRASILEIRO DE ENGENHARIA SANITÁRIA E AMBIENTAL, 12. Anais. Natal: ABES, 2014

SILVA, M. M. P.; ARAÚJO, E. S. A.; SOUSA, M. A.; SILVA, A. V.; SANTOS SOBRINHO, J. B.. Educação Ambiental como Instrumento de Mudança Social e Ambiental, Campina
Grande-PB. In: CONGRESSO BRASILEIRO DE ENGENHARIA SANITÁRIA E AMBIENTAL, 30. Anais. Natal: ABES, 2019.

SILVA, M. M. P.; LIMA, R. A.; GOMES, R. B.; MENDES, R. A.; SANTOS SOBRINHO, J. B.; ARAÚJO, E. C. S.; LIMA, V. G. S.; BARBOSA, G. F.. Educação ambiental: ferramenta indispensável à gestão municipal de resíduos sólidos. Brazilian Journal of Development, v.6, n.5, p.28743-28757, 2020.

SILVA, M. M. P.; SOUSA, M. M. U.; SANTOS, B. D.; COSTA, M. P.; SOARES, E. S.; RIBEIRO, L. A.; CAVALCANTE, L. P. S.. Tecnologias sociais para gestão de resíduos sólidos recicláveis secos e prevenção de riscos no exercício profissional de catadores de materiais recicláveis. Brazilian Journal of Development, v.6, n.3, p.14951-14978, 2020a.

SILVA, M. M. P.; GOMES, R. B.; ARAÚJO, E. C. S.; GOMES, I.; FREITAS, A. F.; SILVA, A. V.; LEITE, V. D.. Prevalência de helmintos em resíduos sólidos orgânicos domiciliares; um risco à saúde ambiental e humana. Brazilian Journal of Development, v.6, n.5, p.28689-28702, 2020b.

SOUSA, M. U.. Gestão de resíduos sólidos sob a ótica da tecnologia social: uma experiência em Campina Grande-PB. Dissertação (Mestrado em Ciência e Tecnologia Ambiental) Universidade Estadual da Paraíba, Campina Grande, 2018.

TEDESCO, J. M.; GIANEWLLO, C.; BISSANI, C. A.; BOHENEM, H.; VOLKWEISS, S. J.. Análises de solo, plantas e outros materiais. Boletim n. 5. 2 ed. Porto Alegre, 1995.

VALENTE, B. S.; XAVIER1, E. G.; MORSELLI, T. B. G. A.; JAHNKE, D. S.; BRUM, J. R.; CABRERA, B. R. P.; MORAES, P. O.; LOPES, D. C. N.. Fatores que afetam o desenvolvimento da compostagem de resíduos orgânicos. Archivos Zootecnia, v.58, p.59-85, 2009.

VILLAMIZAR, S. C.. Avaliação da qualidade microbiológica de um composto produzido a partir de resíduos animais e vegetais. Dissertação (Mestrado) - Universidade Estadual Paulista, São Paulo, 2014.

YOADA, R. M.; CHIRAWURAH, D.; ADONGO, P. B.. Domestic waste disposal practice and perceptions of private sector waste management in urban Accra. BMC Public Health, 2014.

A CBPC - Companhia Brasileira de Produção Científica (CNPJ: 11.221.422/0001-03) detém os direitos materiais desta publicação. Os direitos referem-se à publicação do trabalho em qualquer parte do mundo, incluindo os direitos às renovações, expansões e disseminações da contribuição, bem como outros direitos subsidiários. Todos os trabalhos publicados eletronicamente poderão posteriormente ser publicados em coletâneas impressas sob coordenação da Sustenere Publishing, da Companhia Brasileira de Produção Científica e seus parceiros autorizados. Os (as) autores (as) preservam os direitos autorais, mas não têm permissão para a publicação da contribuição em outro meio, impresso ou digital, em português ou em tradução. 